\title{
A CERTIFICAÇÃO FLORESTAL PELO FSC®: UM ESTUDO DE CASO
}

\author{
Samantha Nazaré de Paiva ${ }^{1}$, Dimas Agostinho da Silva ${ }^{2}$, Roberto Rochadelli ${ }^{3}$, \\ Roberto Tuyoshi Hosokawa ${ }^{2}$, Cymara Regina Oshiro ${ }^{4}$ \\ ${ }^{1}$ Klabin S.A., Telêmaco Borba, Paraná, Brasil - samantha_paiva@ hotmail.com \\ ${ }^{2}$ Universidade Federal do Paraná, Curitiba, Paraná, Brasil - dimass@ufpr.br; roberto.hosokawa @pq.cnpq.br \\ ${ }^{3}$ Universidade Federal do Paraná, Palotina, Paraná, Brasil - nashtell @ufpr.br \\ ${ }^{4}$ Universidade Federal do Paraná, Programa de Pós-Graduação em Engenharia Florestal, Curitiba, Paraná, Brasil - \\ cymara_regina@yahoo.com.br
}

Recebido para publicação: 29/11/2012 - Aceito para publicação: 24/09/2014

\begin{abstract}
O setor florestal tem investido nas últimas décadas em modificações nos processos produtivos, buscando aliar a produtividade com a minimização dos impactos ambientais e sociais negativos que são intrínsecos às suas atividades. Nesse sentido, a certificação florestal é um instrumento de diferenciação no mercado e atualmente se tornou fundamental no segmento de celulose e papel, principalmente para empresas cuja produção é destinada à exportação. Dessa forma, a fim de avaliar as reais vantagens ambientais, sociais e econômicas do processo de certificação florestal pelo FSC (Forest Stewardship Council), bem como as alterações operacionais resultantes do apontamento de desvios normativos, foram analisados os relatórios da certificação e seus respectivos monitoramentos anuais e recertificações, no período compreendido entre os anos de 1998 e 2011, da empresa Klabin S.A. Os desvios apontados em auditorias resultaram em melhorias operacionais nos princípios ambiental, social e econômico, consolidando e dando sustentabilidade às atividades do setor florestal na região de influência da empresa.

Palavras-chave: Papel e celulose; sustentabilidade; manejo florestal.
\end{abstract}

Resumo

\begin{abstract}
The forest certification by FSC: case study. In recent decades, the forest sector has invested into changes in production processes, searching for the combination of productivity with the reduction of negative environmental and social impacts that are intrinsic to their activities. In this sense, forest certification is an instrument of differentiation in the market and today becomes fundamental in the pulp and paper segment, mainly for companies whose production is exported. Thus, in order to assess the real environmental, social and economic benefits of forest certification process by the FSC (Forest Stewardship Council) as well as operational changes resulting from normative deviations appointed, there were analyzed the reports of the certification and their respective monitoring and annual recertifications for the period between 1998 and 2011 of the company Klabin SA. Deviations pointed at audits resulted in operational improvements at the sectors environmental, social and economic, consolidating and giving sustainability to the forest sector in the region of company influence.

Keywords: Pulp and paper; sustainability; forest management.
\end{abstract}

\section{INTRODUÇÃO}

A crescente inserção do aspecto ambiental nas relações de comércio fez emergir um novo conceito de gestão, que passou a incorporar essa variável como fator de eficiência quantitativa e qualitativa nos sistemas produtivos. Essa prerrogativa vem ao encontro do aumento, em número, de certificações de cunho ambiental, refletindo a preocupação de diferentes setores da sociedade que passaram a exigir produtos ambientalmente sustentáveis.

As pressões públicas locais, nacionais e mesmo internacionais, segundo Yong e Lustosa (2002), exigem mais responsabilidade ambiental das empresas. Bancos, financiadores e seguradoras dão privilégios a empresas ambientalmente sadias, ou taxas financeiras e valores de apólices mais elevadas de

FLORESTA, Curitiba, PR, v. 45, n. 2, p. 213 - 222, abr. / jun. 2015.

Paiva, S. N. de et al.

ISSN eletrônico 1982-4688 / ISSN impresso 0015-3826 
firmas poluidoras. Organizações não governamentais estão mais vigilantes, exigindo o cumprimento da legislação ambiental, a minimização de impactos e a reparação de danos ambientais, ou impedindo a implantação de novos empreendimentos ou atividades (MAIMON, 1999). A imagem de empresas ambientalmente saudáveis é mais bem aceita por acionistas, consumidores, fornecedores e autoridades públicas, nas quais acionistas conscientes da responsabilidade ambiental preferem investir (MAIMON, 1999).

Dessa forma, a busca por certificações voluntárias passou a ser uma estratégia de negócios, principalmente na busca por nichos de mercado específicos, cuja exigência de certificações como o FSC (Forest Stewardship Council) é prerrogativa para o estabelecimento do negócio.

As certificações de "Bom Manejo Florestal" apesar de ser prática recente, apresenta uma série de vantagens para quem é certificado (GOMES, 2011). Colaboram para a imagem de empresas desse segmento, principalmente no que se refere ao seu engajamento na região onde a sua base florestal está presente, e passam também a ser consideradas como instrumento adicional para garantir o uso racional de recursos florestais, de forma ambientalmente correta, socialmente justa e economicamente viável, no cumprimento de todas as leis vigentes.

Em resposta às pressões ambientais, o segmento de celulose e papel do setor de base florestal tem promovido inovações e capacitações tecnológicas para melhorar seus processos, com destaque à otimização da água em seu processo produtivo e a substituição do cloro elementar no branqueamento por tecnologias limpas, como a utilização de ozônio (OLIVEIRA, 2011). Da mesma forma, a adoção da certificação, que é um processo voluntário, avalia a conformidade das atividades praticadas pelos empreendimentos a partir de critérios normativos (CAETANO, 2011). É realizada através de uma organização creditada, ou seja, isenta de interesses, que certifica que todos os requisitos do processo produtivo e que suas avaliações e decisões são sólidas (NUSSBAUM; SIMULA, 2005).

Através da análise dos relatórios de acreditação periódicos e do monitoramento anual de uma empresa, é possível verificar as não conformidades dos processos e procedimentos florestais em âmbito sistêmico, como ditam os princípios e critérios do FSC, e assim promover ações e medidas corretivas para a obtenção da Certificação.

Assim, o objetivo do presente artigo consistiu na verificação da ocorrência ou não de ganhos ambientais e sociais, tanto no próprio empreendimento quanto na região de influência, desde o processo de certificação, bem como a influência da certificação nas alterações de processos operacionais ocorrentes, a partir do apontamento dos desvios normativos da norma FSC.

\section{MATERIAIS E MÉTODOS}

O presente trabalho foi desenvolvido em uma unidade da empresa de base florestal Klabin S.A., localizada no interior do estado do Paraná, no município-sede de Telêmaco Borba.

Uma das características da região é a predominância de pequenas propriedades localizadas em municípios com menos de 70 anos de criação, constituídos de população inferior a 60 mil habitantes/município e grande parte com baixo Índice de Desenvolvimento Humano (IDH). A vocação da região é limitada a serviços agropecuários e silvipastoris. O setor de serviços possui baixa capacidade de dinamização da economia local, com exceção ao município de Telêmaco Borba, onde se localiza a base industrial da empresa (INSTITUTO BRASILEIRO DE GEOGRAFIA E ESTATÍSTICA (IBGE), 2012).

Foram realizadas entrevistas semiestruturadas junto aos profissionais engajados no processo de certificação, de diferentes níveis hierárquicos, formando a base para a busca de informações nos relatórios internos da empresa e nos processos correlatos e necessários para o levantamento de dados.

O levantamento de dados foi realizado por meio de verificação e análise dos relatórios de auditoria (diagnóstico inicial, auditoria principal e monitoramentos) de certificação florestal da empresa Klabin S.A., unidade de manejo de florestas plantadas, pelo sistema FSC, durante o período compreendido entre 1998 e 2011.

Os relatórios são parte do processo de auditoria que é elaborado pela equipe após o processo, que envolve entrevistas e verificação em campo e análises documentais, com anuência e aprovação pela equipe auditada. Neles estão descritas informações pertinentes à organização, como localização e abrangência do escopo certificado, além de informações obrigatórias, como evidências do desempenho da organização perante as conformidades do padrão normativo e as solicitações de ações corretivas e/ou as

FLORESTA, Curitiba, PR, v. 45, n. 2, p. 213 - 222, abr. / jun. 2015. 
observações e recomendações de melhoria. As tratativas quanto ao fechamento e acompanhamento de ações corretivas de anos anteriores também são descritas. É importante ressaltar que esse documento é restrito à certificadora e à organização avaliada, enquanto o resumo é disponibilizado no site da organização Rainforest Alliance (RAINFOREST ALLIANCE, 2012).

Os parâmetros avaliados nos relatórios foram referentes aos princípios e critérios da certificação FSC (2006):

- Princípio 1: Obediência às Leis e aos Princípios do FSC. Critérios: o manejo florestal deve respeitar todas as leis aplicáveis ao país onde opera, os tratados internacionais e acordos assinados por este país, e obedecer a todos os princípios e critérios do FSC.

- Princípio 2: Responsabilidades e direitos de posse e uso da terra. Critérios: os direitos de posse e uso de longo prazo relativos à terra e aos recursos florestais devem ser claramente definidos, documentados e legalmente estabelecidos.

- Princípio 3: Direitos dos povos indígenas. Critérios: os direitos legais e costumes dos povos indígenas de possuir, usar e manejar suas terras, territórios e recursos devem ser reconhecidos e respeitados.

- Princípio 4: Relações comunitárias e direito dos trabalhadores. Critérios: as atividades de manejo florestal devem manter ou ampliar o bem-estar econômico e social de longo prazo dos trabalhadores florestais e das comunidades locais.

- Princípio 5: Benefícios da floresta. Critérios: as operações de manejo florestal devem incentivar o uso eficiente dos múltiplos produtos e serviços da floresta para assegurar a viabilidade econômica e uma grande gama de benefícios ambientais e sociais.

- Princípio 6: Impacto ambiental. Critérios: o manejo florestal deve conservar a diversidade ecológica e seus valores associados, os recursos hídricos, os solos e os ecossistemas e paisagens frágeis e singulares, e assim atuar, manter as funções ecológicas e a integridade da floresta.

- Princípio 7: Plano de manejo. Critérios: um plano de manejo, apropriado à escala e intensidade das operações propostas deve ser escrito, implementado e atualizado. Os objetivos de longo prazo do manejo florestal e os meios para atingi-los devem ser claramente definidos.

- Princípio 8: Monitoramento e avaliação. Critérios: o monitoramento deve ser conduzido, apropriado à escala e à intensidade do manejo florestal, para que sejam avaliados a condição da floresta, o rendimento dos produtos florestais, a cadeia de custódia, as atividades de manejo e seus impactos ambientais e sociais.

- Princípio 9: Manutenção de florestas de alto valor de conservação. Critérios: as atividades de manejo de florestas de alto valor de conservação devem manter ou ampliar os atributos que definem essas florestas. Decisões relacionadas às florestas de alto valor de conservação devem sempre ser consideradas no contexto de uma abordagem precatória.

- Princípio 10: Plantações. Critérios: as plantações devem ser planejadas e manejadas de acordo com os princípios e critérios de 1 a 9, e o princípio 10 e seus critérios. Considerando que as plantações podem proporcionar um leque de benefícios sociais e econômicos e contribuir para satisfazer as necessidades globais por produtos florestais, recomenda-se que elas complementem o manejo, reduzam as pressões e promovam a restauração e conservação das florestas naturais.

A empresa avaliada neste trabalho é certificada pelo FSC, de forma que a compreensão de sua concepção é fundamental para o entendimento das vantagens associadas a esse processo.

Os desvios relativos aos parâmetros normativos do FSC podem ser evidenciados através do estabelecimento de não conformidades maiores, menores e observações, que são registradas em relatórios.

Os desvios normativos ocorridos nas auditorias de certificação e monitoramentos anuais são aqui caracterizados como não conformidade maior e não conformidade menor, ou ainda apontados como observações/recomendações pelos processos de auditorias externas, ou seja, realizados pela certificadora, nos anos de 2000 a 2011. Esses dados foram compilados a partir dos relatórios de auditorias.

Dados da região de influência do empreendimento, a fim de avaliar o contexto socioeconômico, foram consultados através dos sites de referência governamentais, tais como Instituto Paranaense de Desenvolvimento Econômico e Social (IPARDES), Instituto Brasileiro de Geografia e Estatística (IBGE) e Portal ODM (Acompanhamento Municipal dos Objetivos do Desenvolvimento do Milênio). As interferências regionais puderam ser verificadas a partir das observações do processo de certificação, do

FLORESTA, Curitiba, PR, v. 45, n. 2, p. 213 - 222, abr. / jun. 2015.

Paiva, S. N. de et al. 
crescimento da empresa e das expectativas de desenvolvimento regional, conforme projetos e programas da empresa.

A partir da organização dos dados, foi realizada a análise, buscando-se a relação entre as variáveis, como desvios apontados, recorrência dos assuntos abordados em auditorias de monitoramento, práticas influenciadas na unidade de manejo, recertificação e certificação.

\section{RESULTADOS E DISCUSSÃO}

A unidade florestal da Klabin S.A., cuja base florestal está localizada na região de Telêmaco Borba, foi inicialmente certificada pelas práticas de manejo florestal através do FSC em 1998. Atualmente, encontra-se no terceiro ciclo de certificação, ou seja, passou por 3 ciclos de auditorias, que compreendem 5 anos cada, em que todos os princípios e critérios são verificados, e por monitoramentos anuais, em que dois ou três princípios são avaliados visando monitorar o desempenho do manejo florestal. A cada processo de auditoria e monitoramento, são emitidos os relatórios referentes às conformidades ou não dos critérios de certificação.

Deve-se destacar que a empresa foi a primeira do segmento de papel e celulose no Brasil a buscar a certificação florestal e, devido à essa característica inovadora, o processo de certificação do manejo florestal tornou-se um aprendizado contínuo, tanto para a equipe certificadora quanto para a empresa. Os desvios normativos (não conformidades) são resumidos abaixo e ilustrados na figura 1.

$\mathrm{Na}$ primeira certificação, realizada em 1998, como requisitos para a certificação, foram abordados temas referentes à ausência de procedimentos e melhoria da gestão de processos já existentes. A certificadora concedeu prazos para os ajustes que variaram de 3 a 24 meses, dependendo da complexidade das atividades envolvidas, e que foram acompanhados durante os monitoramentos anuais. Os temas abordados nesse primeiro ciclo de certificação (1998 a 2002) foram:

- Princípio 2: Ausência de um gerenciamento ambiental contendo: qualidade da água, perdas de solo, tamanho mínimo de área de corte raso, danos a áreas de preservação permanente e áreas de conservação, ausência de um programa de conservação de bacias hidrográficas e inclusão no planejamento de longo prazo do manejo da paisagem, definindo diretrizes para a manutenção e/ou aumento da heterogeneidade e conectividade de fragmentos florestais.

- Princípio 4: Melhoria do cadastro da propriedade e de áreas de fomento, possibilitando a identificação de espécies plantadas, data de plantio, dimensão de áreas de preservação e conservação; ausência de um programa de acompanhamento das empresas prestadoras de serviço do setor florestal, com descrição de benefícios e remuneração; implantação de um programa de produção de mudas de espécies nativas para plantio em área degradada e de fomento.

- Princípio 6: Realização de melhorias operacionais no sistema de colheita, minimizando impactos ambientais.

- Princípio 7: Levantamento de impactos socioambientais nas comunidades vizinhas ao empreendimento; definição de uma política clara de diálogo entre a empresa e o sindicato de trabalhadores rurais que não implique em ingerência, mas reconheça a legitimidade e a importância estratégica desse setor social para a realidade regional; melhoria dos procedimentos para atendimento de demandas sociais de forma a garantir respostas em prazo determinado.

- Princípio 8: Ausência de análise de impactos socioeconômicos da instalação de empresas de beneficiamento de madeira no município de Telêmaco Borba; implantação de um programa para incentivar a adoção dos princípios e critérios do FSC entre os participantes do programa de fomento florestal e elaboração de um programa voltado aos funcionários demitidos pela adoção de inovações tecnológicas nos processos produtivos.

No segundo ciclo da certificação (2003-2007), foram apontadas 21 não conformidades:

- Princípio 1: Averbação de todas as áreas de reserva legal e status das áreas de preservação permanente.

- Princípio 4: Controle legal (monitoramento trabalhista) de prestadores de serviço.

- Princípio 6: Eliminação do processo de queima de resíduos florestais na unidade de manejo; implementação de metodologia para avaliação de pré e pós-operações; eliminação de espécies exóticas (pínus) em áreas de florestas nativas; definição de manejo de áreas de plantios de araucária 
como banco de germoplasma e conservação da espécie.

- Princípio 7: Elaboração de um plano de manejo para RPPN de Monte Alegre.

- Princípio 8: Monitoramentos sociais, ambientais e legais com maior frequência.

- Princípio 9: Definição de áreas com atributos para FAVC (florestas de alto valor de conservação).

Esse ciclo evidenciou a necessidade do cumprimento do princípio 9 (FAVC), anteriormente compreendido e validado para florestas nativas manejadas, que passou a ser aplicado para florestas plantadas, com o entendimento de que estas também devem identificar os atributos de alto valor de conservação, gerando o desenvolvimento e validação de nova metodologia.

O processo de recertificação do terceiro ciclo (2007-2011) apontaram 18 não conformidades:

- Princípio 1: Acompanhamento de processos de outorga para captação de água.

- Princípio 4: Acompanhamento e realização de treinamentos obrigatórios derivados de regulamentações; excesso de jornada de trabalho para motoristas em prestadores de serviço na organização; utilização de EPIs (equipamento de proteção individual) em atividades específicas no processo florestal.

Observou-se que no ordenamento temporal da certificação o processo foi adquirindo maturidade, com os desvios levantados no terceiro ciclo já não sendo pertinentes a questões amplas relacionadas à operação, passando a ser apontados os aspectos sociais. Ou seja, na medida em que as não conformidades foram sendo apontadas, medidas corretivas foram sendo executadas, permitindo a visualização de outras não conformidades e outros parâmetros.

A figura 1 apresenta os apontamentos realizados por Princípios do FSC, indicando que nos anos de 2007 e 2008 houve uma maior percepção dos aspectos sociais (P4) pela equipe auditora, da comunidade tanto interna quanto externa. É importante ressaltar que no processo de certificação há a prática de verificação dos problemas apontados em anos anteriores, para fechamento das ações corretivas, e quando as correções não podem ser evidenciadas, o desvio é novamente apontado, mas em uma maior classificação.

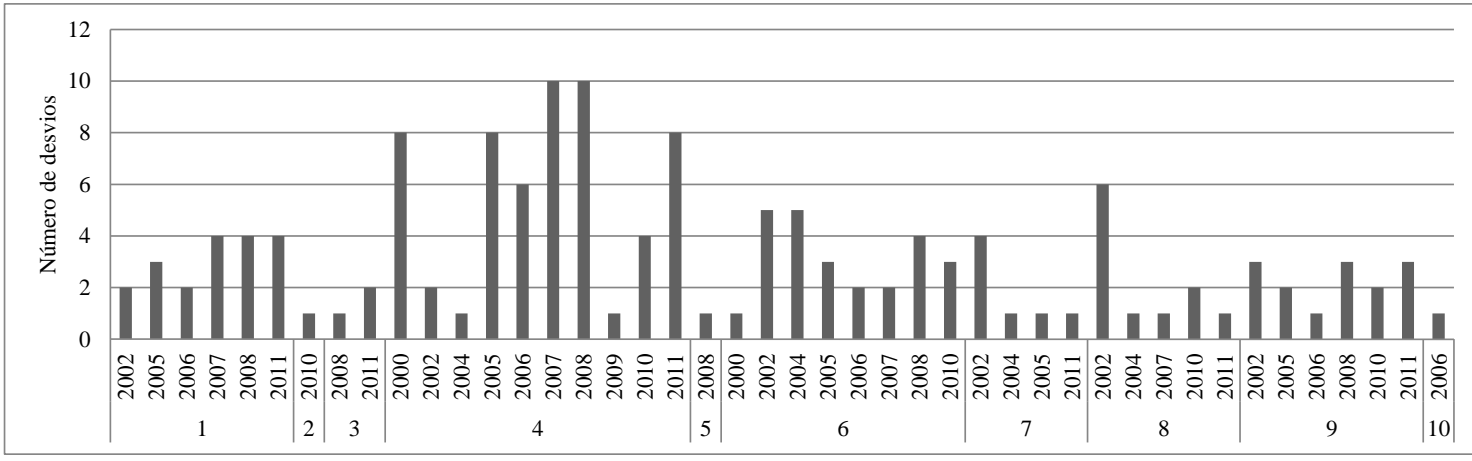

Figura 1. Desvios normativos apontados nas auditorias de certificação e monitoramento relacionados aos princípios 1 a 10 do FSC na unidade de manejo florestal - Klabin S.A., Paraná (2000-2011).

Figure 1. Deviations standards appointed in the certification audits and the monitoring audits of the 1 to 10 FSC principles of forest management - Klabin S.A., Paraná (2000-2011).

Os dados apontam que os princípios 2 (direito de posse e uso da terra), 5 (benefícios da floresta) e 10 (plantações) foram os que apresentaram menos ocorrências de não conformidades, o que indica que a empresa preza pela regularização territorial e utiliza tecnologia e sistema de gestão para suas áreas de plantios florestais. Da mesma forma é demonstrado na evolução dos princípios 7 (plano de manejo) e 8 (monitoramento e avaliação) que as medidas corretivas foram sendo aplicadas a partir do apontamento das não conformidades.

O princípio com maior número de desvios, num total de 60 , é o $4^{\circ}$, que representa as Relações Comunitárias e os Direitos dos Trabalhadores. Os relatórios apontaram, em relação a esse princípio, não conformidades menores referentes ao monitoramento quanto aos aspectos de segurança e programas de reciclagem de treinamentos (em 2000). Já em 2011, as não conformidades apontaram para equipamentos de segurança (EPI). A evolução temporal demonstrada no princípio $4^{\circ}$ indica que, inicialmente, foram cobrados os aspectos de segurança e, à medida que foram realizadas correções iniciais, novas não conformidades

FLORESTA, Curitiba, PR, v. 45, n. 2, p. 213 - 222, abr. / jun. 2015.

Paiva, S. N. de et al.

ISSN eletrônico 1982-4688 / ISSN impresso 0015-3826

DOI: $10.5380 /$ rf.v45i2.30055 
emergiram e passaram a ser exigidas, além dos aspectos legais, como por exemplo a exigência de dois pares de botas para trabalhadores operacionais.

É importante ressaltar algumas práticas geradas por influência da certificação, tanto para o público interno (funcionários próprios e funcionários de empresas prestadoras de serviço) quanto para o público externo (partes interessadas no empreendimento avaliado). Algumas dessas práticas serão aqui destacadas, segregadas pelos temas ambiental, social e econômico.

\section{Tema ambiental}

Do ponto de vista ambiental, a organização passa a ter melhor gestão sob os recursos naturais, incluindo a influência clara em parceiros, como aqueles com contratos de fomento florestal. É também visível a implementação de monitoramentos: fauna, flora, recursos hídricos e pontos frágeis para as operações florestais.

Na tabela 1 são apresentados os resultados decorrentes de práticas florestais realizadas na unidade de manejo da empresa nos anos de 2000 a 2008.

Tabela 1. Resultado de práticas florestais influenciadas na unidade de manejo.

Table 1. Results of the forest operation influence on the management unit.

\begin{tabular}{ll}
\hline Ano do desvio & Prática influenciada na unidade de manejo \\
\hline 2000 & Procedimento de colheita evidenciando a minimização de danos às matas nativas. \\
2003 & Identificação de plantios de araucária para conservação mediante a sua importância para o \\
& manejo da paisagem regional. \\
& Identificação de indivíduos arbóreos nativos importantes para a conservação mediante a sua \\
& importância para o manejo da paisagem regional. \\
& Estabelecimento de auditorias internas periódicas. \\
& Plano de monitoramento de bacias hidrográficas. \\
& Acompanhamento sistemático de contratos de arrendamento florestal. \\
& Eliminação do processo de queima - somente para fins sanitários. \\
& Procedimento para retirada de espécies exóticas de APP. \\
& Monitoramento de fauna e flora em Áreas de Alto Valor de Conservação. \\
& Levantamento de legislação (Federal, Estadual e Municipal) de forma sistemática. \\
& Sistemática de identificação de pontos com erosão. \\
& Seleção de áreas de Alto Valor de Conservação.
\end{tabular}

A figura 2 apresenta, de forma gráfica, a temporalidade das práticas operacionais, representada pelos eventos significativos no processo de certificação de manejo florestal da empresa, compiladas a partir da análise de relatórios internos desde a década de 60 (século XX). Podem ser verificados os ganhos ambientais, tendo nas ações dos anos 70 e na recuperação das áreas degradadas o atendimento ao Princípio 6 do FSC, que se refere aos impactos ambientais. Verifica-se que a percepção ambiental é anterior ao processo de certificação e que após a instalação do processo as correções aos apontamentos de auditoria resultaram em recuperação de áreas de preservação permanente e de áreas degradadas e na manutenção das áreas envolvidas no processo produtivo, o que atende ao Princípio 1. Da mesma forma, a diminuição da densidade de estradas obedece ao Princípio 4, auxiliando no bem-estar social da comunidade lindeira. As ações, em seu conjunto, proporcionaram ganhos ambientais para o manejo de bacias hidrográficas da área em contexto.

Importante salientar, que os resultados apresentam temas recorrentes quanto à melhoria da gestão ambiental, incluindo práticas de monitoramento de fauna e flora e seleção de áreas de Alto Valor de Conservação.

\section{Tema social}

Silva (2008) ressalta que a atividade de papel e celulose tem alta influência social no que se refere às classes sociais e ao atendimento das condições de saúde, escolaridade, bem-estar e infraestrutura. A população é atraída para os núcleos industriais em busca de emprego, e o aumento demográfico despreparado impacta negativamente no desenvolvimento local. A autora salienta ainda que "a Klabin desencadeia impactos negativos às questões sociais quando não planeja em conjunto com o município seus projetos de expansão". Mesmo a empresa promovendo ações de responsabilidade social, a velocidade de incremento populacional tende a ser maior que as ações preventivas dos impactos (aumento do custo de 
vida, dificuldade de acesso aos serviços sociais e aumento da criminalidade).

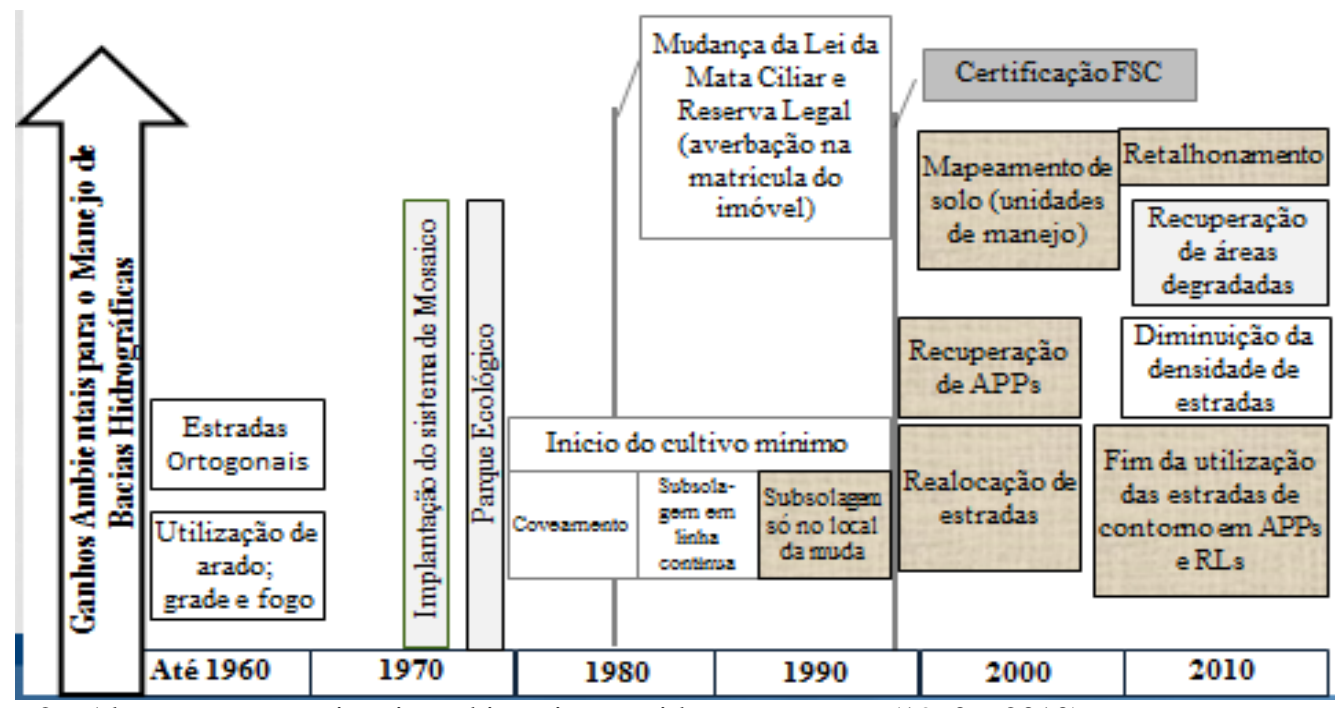

Figura 2. Alterações operacionais ambientais ocorridas na empresa (1960 a 2010).

Figure 2. Operational changes at the company related to the environment (1960-2010).

Do ponto de vista social, a empresa passou a ter práticas mais representativas, que são apresentadas na tabela 2, destacando os resultados para as comunidades interna e externa à empresa.

Tabela 2. Práticas referentes ao tema social para a comunidade interna e externa da empresa.

Table 2. Experiences concerning social theme in the community around the company areas.

\begin{tabular}{lcl}
\hline Classificação & Ano do desvio & Prática influenciada na unidade de manejo \\
\hline $\begin{array}{l}\text { Comunidade } \\
\text { interna }\end{array}$ & 2002 & $\begin{array}{l}\text { Monitoramento legal e trabalhista em empresas terceiras. } \\
\text { Implantação de CIPA (Comissão Interna de Prevenção a Acidentes) em todos } \\
\text { os prestadores de serviço. } \\
\text { Programa Crescer (educação continuada em parceria com o SESI - Serviço } \\
\text { Social na Indústria). } \\
\text { Procedimento para desligamento dos trabalhadores de empresas terceiras. }\end{array}$ \\
\hline \multirow{2}{*}{$\begin{array}{l}\text { Comunidade } \\
\text { externa }\end{array}$} & 2006 & $\begin{array}{l}\text { Fortalecimento da divulgação dos canais de comunicação formais. } \\
\text { Estreitamento do relacionamento com os sindicatos atuantes no segmento. }\end{array}$ \\
& 2008 & $\begin{array}{l}\text { Identificação de comunidades indígenas e quilombolas na área de influência. } \\
\text { Levantamento de impactos sociais na área de influência. } \\
\text { Sistematização do levantamento e identificação de elementos sociais } \\
\text { (povoados, vilas, igrejas, cemitérios etc.) em rotas utilizadas no transporte } \\
\text { florestal. }\end{array}$ \\
\hline
\end{tabular}

Com relação à comunidade interna, ou seja, funcionários próprios e de empresas prestadoras de serviço que atuam nas propriedades da empresa e sob a sua supervisão, importantes avanços foram realizados, sendo o principal a implantação de monitoramento legal e trabalhista em empresas terceirizadas, permitindo a verificação prévia de desvios e estabelecendo planos para acompanhamento da resolução. Essa ação é importante para a manutenção da certificação e da relação com fornecedores e respectivos colaboradores. A implementação de programas de educação continuada também exerce um papel fundamental nessa relação, uma vez que é um meio de comunicação formal e estabelecido com a força de trabalho terceirizada.

Com a comunidade externa, foram consolidados os meios de comunicação e sistematizada a sua divulgação, estreitando o relacionamento com a comunidade no entorno do empreendimento e junto aos sindicatos de atuação. O diálogo existente entre as comunidades tradicionais e as comunidades indígenas presentes na região torna-se mais eficaz, ou seja, a empresa, além de conhecer a localização dessas

FLORESTA, Curitiba, PR, v. 45, n. 2, p. 213 - 222, abr. / jun. 2015.

Paiva, S. N. de et al.

ISSN eletrônico 1982-4688 / ISSN impresso 0015-3826

DOI: $10.5380 /$ rf.v45i2.30055 
comunidades, passa a ouvir e registrar as demandas e a vislumbrar meios de sanar as eventuais dúvidas sobre os processos operacionais.

Importante, ainda, salientar que alguns desvios apresentados foram identificados como recorrentes, ou seja, estavam presentes em diferentes momentos, tanto de auditorias de monitoramento como de auditorias de certificação.

Isso ocorre porque as soluções pontuais, retratadas em planos de ação, não foram eficientes, seja na identificação da causa raiz do problema, seja na abrangência do mesmo. Pode-se citar como exemplo dessa afirmação a utilização correta de EPI (Norma Regulamentadora n ${ }^{\circ}$ 6, do Ministério do Trabalho e Emprego). Entretanto, é importante ressaltar que esses problemas são intrínsecos à atividade florestal, já que, no primeiro caso, há uma deficiência tecnológica, ou seja, existem equipamentos que realizam o carregamento no campo ainda não tão eficazes e confiáveis a ponto de atender as especificações contidas na legislação (LOPES et al., 2006).

Já no segundo exemplo, no que se refere à utilização de EPI por parte dos trabalhadores florestais, há grande dificuldade de conscientização e cumprimento de exigências operacionais, além de existir, ainda, um descrédito quanto aos perigos associados às atividades florestais, conforme orienta a Norma Regulamentadora $\mathrm{n}^{\circ} 31$ do Ministério do Trabalho e Emprego, sobre segurança e saúde no trabalho na agricultura, pecuária, silvicultura, exploração florestal e aquicultura.

\section{Tema econômico}

A partir do momento em que são avaliadas as questões econômicas, o município de Telêmaco Borba se destaca na região dos Campos Gerais do Paraná, sendo que um dos motivos é a dinamização da economia em função da presença da empresa, direta ou indiretamente.

Um exemplo que deve ser citado é o parque industrial do município de Telêmaco Borba, criado através da Lei 784 PRODEFI (Programa de Desenvolvimento e Fomento Industrial), de 27 de março de 1989, a partir de uma parceria com a Universidade Estadual de Ponta Grossa (UEPG), para identificar a vocação do município (TELÊMACO BORBA, 2012).

Atualmente, abriga mais de 60 empresas do ramo madeireiro, gerando cerca de 3000 empregos diretos, em diversos segmentos, como metalurgia, reciclagem, medicamentos genéricos, molduras, móveis, tubetes de papel, aproveitamento de celulose, alimentos, cola para papel, pallets, substrato de casca de madeira, produtos de concreto, forros, assoalhos, vigas coladas, cabos e indústrias de reaproveitamento de resíduos de madeira (TELÊMACO BORBA, 2012).

Estudos realizados por Silva (2008) apontam que a indústria de papel e celulose tem influência no desenvolvimento da região de Telêmaco Borba, contribuindo para a melhoria do nível de escolaridade e renda. Quanto maior a atividade econômica, maior a demanda sobre a "base local", o que tornou a Klabin S.A. a alavanca para o desenvolvimento de outras atividades econômicas, principalmente por ser a região ainda dependente da dinâmica da empresa. A empresa, como agente local, pratica ações de responsabilidade social e investe na instalação e na estrutura da base local. Por outro lado, ela necessita de recursos humanos qualificados.

Quanto à origem da mão de obra, Betim (2007) aponta que 97,8\% dos funcionários são originários do próprio município, e somente 2,2\% são provenientes dos municípios vizinhos, como Imbaú, Curiúva e Ventania. A autora ressalta ainda os fatores decisivos para a escolha do município nos investimentos realizados pelos empresários, dos quais se destacam:

(i) acesso e proximidade com os fornecedores de matéria-prima/insumos - interferência forte em 91,7\% dos entrevistados;

(ii) infraestrutura disponível - interferência forte em $27,8 \%$ e considerável em 55,5\%;

(iii) disponibilidade da mão de obra - interferência forte em 19,4\% e considerável em 66,7\%.

$\mathrm{O}$ volume de produção das empresas do distrito industrial está ligado diretamente ao fornecimento de matéria-prima. Nesse caso, a Klabin S.A. é apontada pelas empresas como a principal fornecedora de madeira manejada e certificada pelo Conselho de Manejo Florestal, FSC (Forest Stewardship Council) (BETIM, 2007). Importante ressaltar que, em função da comercialização dos produtos, é exigência, principalmente para exportação, que a madeira seja certificada.

Dessa forma, evidencia-se que a certificação do manejo florestal e da cadeia de custódia da empresa Klabin S.A., unidade PR, é importante para o desenvolvimento regional, principalmente no que se refere ao segmento madeireiro. Essa afirmação vem ao encontro do trabalho de Almeida et al. (2012), que 
avaliou a influência da Klabin S.A. no mercado de tora de madeira no estado do Paraná e ressalta que as empresas do processamento mecânico dependentes do fornecimento de madeira certificada não pagam um preço superior ao praticado no Estado. O mesmo autor aponta também que não é possível afirmar que a empresa utilizou o seu poder de mercado em busca de aumento do seu lucro na compra ou venda de madeira no ano de 2008.

Em 2013, a empresa lançou o Projeto Puma, com a construção de uma nova unidade no município de Ortigueira, PR, para a produção de 1,5 milhão de toneladas de celulose por ano. $\mathrm{O}$ empreendimento deverá ser instalado em 2015, com o investimento de $\mathrm{R} \$ 6,8$ bilhões e a criação de 8,5 mil empregos diretos e indiretos na fase de construção e 1400 postos para a operação da fábrica. Ponto importante do projeto é a divisão de Imposto sobre Circulação de Mercadorias e Serviços (ICMS) entre os 12 municípios da região de baixo Índice de Desenvolvimento Humano (IDH), criando a perspectiva de ganhos econômicos e sociais, aumentando a renda para a região e atraindo novas empresas, oportunidades de empregos, aumento na demanda para o setor de serviços, formação e qualificação profissional e melhoria da infraestrutura regional.

\section{CONCLUSÃO}

A certificação florestal agregou valor para a gestão operacional da empresa estudada. Os desvios normativos apontados em auditorias do FSC foram identificados e direcionaram ações para a melhoria do processo operacional, garantindo a sustentabilidade das operações, nos pilares econômico, social e ambiental.

No que se refere às vantagens, a certificação florestal apresentou-se positiva tanto para a sociedade como para o empreendimento, destacando-se:

- $\quad$ socioeconômico - contratação e formação de mão de obra local, contratação de serviços, bem como presença de projetos sociais, ambientais e educacionais;

- $\quad$ sociais - monitoramentos periódicos de mão de obra, formalização de canais de comunicação;

- ambiental: melhor gerenciamento de recursos hídricos e de monitoramentos.

A certificação FSC consolida, portanto, a vocação da região onde a empresa avaliada está localizada para a economia baseada em produtos florestais.

\section{REFERÊNCIAS}

ALMEIDA, A. N.; SILVA, J. C. G. L.; ANGELO, H. Influência da Klabin no mercado de madeira em tora do estado do Paraná. Cerne, Lavras, v. 18, n. 1, p. 153 - 158, 2012.

BETIM, L. M. Caracterização da estrutura organizacional do aglomerado produtivo de Telêmaco Borba, PR. 2007. Dissertação (Mestrado em Engenharia da Produção) - Universidade Tecnológica Federal do Paraná, Campus Ponta Grossa, Ponta Grossa, 2007.

CAETANO, M. A. L. A certificação florestal como instrumento político. 76 f. Dissertação (Mestrado em Engenharia Florestal e dos Recursos Naturais). Instituto Superior de Agronomia - Universidade Técnica de Lisboa, Lisboa, 2011.

FSC Brasil. Padrão Normativo. 2006. Disponível em: <www.fsc.org.br>. Acesso em: 5 de junho de 2012.

GOMES, I. M. B. Segmento brasileiro de polpa celulósica: evolução, competitividade e inovação. $155 \mathrm{f}$. Tese (Doutorado em Economia Aplicada) - Escola Superior de Agricultura Luiz de Queiroz, Universidade de São Paulo, Piracicaba, 2011.

INSTITUTO BRASILEIRO DE GEOGRAFIA E ESTATÍSTICA (IBGE). Disponível em: <http://www. ibge.gov.br/home/estatistica/populacao/censo2010/default.shtm>. Acesso em: 11 de julho de 2012.

INSTITUTO PARANAENSE DE DESENVOLVIMENTO ECONÔMICO E SOCIAL (IPARDES). Relatórios Municipais - 2007. Disponível em: 〈http://www.ipardes.pr. gov.br〉. Acesso em: 19 de julho de 2012.

KLABIN S.A. Informações gerais da empresa. 2012. Disponível em: <www.klabin.com.br〉. Acesso em: 11 de julho de 2012. 
LOPES, E. S.; CRISTO, J. F. C.; PIEPER, M. Avaliação técnica de um sistema de pesagem no carregamento florestal. Árvore, Viçosa-MG, v. 30, n. 4, p. 575 - 581, 2006.

MAIMON, D. ISO 14001: Passo a passo da implantação nas pequenas e médias empresas. Rio de Janeiro: Qualitymark, 1999.

NUSSBAUM, R.; SIMULA, M. The forest certification handbook. London UK: Earthscan, 2005. 300 p.

OLIVEIRA, P. A. Estratégias de internalização da gestão ambiental: o caso da gestão hídrica na etapa industrial da produção na Companhia Suzano de Papel e Celulose. 105 f. Dissertação (Mestrado em Ciência Ambiental) - Ciência Ambiental, Universidade de São Paulo, São Paulo, 2011.

RAINFOREST ALLIANCE. Certified Forestry Operation Summaries for Brazil. Disponível em: <http://www.rainforest-alliance.org/>. Acesso em: 11 de julho de 2012.

SILVA, H. de P. Sustentabilidade e desenvolvimento local a partir da atividade econômica de celulose e papel: Telêmaco Borba e a Klabin em questão. Dissertação. PPG FAE Centro Universitário, Curso de mestrado acadêmico multidisciplinar em organizações e desenvolvimento (sustentabilidade e desenvolvimento local), Curitiba, PR, 2008.

TELÊMACO BORBA, Prefeitura Municipal, 2012. Disponível em: <http://www.telemacoborba.pr.gov. br>. Acesso em: 18 de julho 2012.

YONG, C. E. F.; LUSTOSA, M. C. Competitividade e meio ambiente: a nova relação centro-periferia. In: BRAGA, A. S.; MIRANDA, L. C. (Org.). Comércio e meio ambiente: uma agenda positiva para o desenvolvimento sustentável. Brasília, DF: Ministério do Meio Ambiente, 2002. p. 41 - 60. 